\title{
A conversão para 0 cinema sonoro no Brasil e o mercado exibidor na década de 1930
}

////////////////// : Rafael de Luna Freire ${ }^{1}$

1. Professor do curso de graduação em cinema e audiovisual da Universidade Federal Fluminense e da Pós-Graduação em

Comunicação da UFF. E-mail: rafaeldeluna@hotmail.com 


\section{Resumo}

O artigo analisa a conversão do circuito cinematográfico exibidor brasileiro para a projeção de filmes sonoros, atentando para as particularidades regionais e para as dimensões tecnológicas e econômicas. Ao examinar como esse processo ocorreu em caráter nacional, são identificadas três fases: a chegada do cinema sonoro às principais cidades brasileiras (1929-1930); a lenta conversão dos circuitos secundários (1931-1933) e as dificuldades geradas pela necessidade de padronização tecnológica (1934-1935).

\section{Palavras-chave}

Cinema sonoro, exibição, tecnologia.

\section{Abstract}

This article analyses the adaptation of Brazilian movie theaters to sound film projection with special attention to the local particularities and its economic and technologic dimensions. It is described how this process took place nationwide, identifying three different phases: the arrival of the talkies in the main Brazilian cities (1929-1930); the slow expansion of sound projection in the secondary circuit (1931-1933); and the difficulties of technology standardization (1934-1935).

\section{Keywords}

Sound film, exhibition, technology. 


\section{Introdução}

A adaptação das salas de cinema das cidades de São Paulo e Rio de Janeiro para a projeção de filmes sonoros foi relativamente rápida. Poucos meses após a inauguração do cinema sonoro no Cine Paramount, em São Paulo, em 13 de abril de 1929, e no Palácio Theatro, no Rio de Janeiro, em 20 de junho do mesmo ano, o circuito de primeira linha dessas cidades já tinha sido convertido para a exibição dos novos talkies. Afinal, esses luxuosos palácios cinematográficos podiam arcar com a compra e instalação dos caros e importados projetores Western Electric conjugados para os sistemas Vitaphone (som em discos) e Movietone (som ótico) (FREIRE, 2012a). Por outro lado, a febre do sincronizado não demorou muito para chegar também aos cinemas de bairro, atingindo o circuito secundário carioca e paulistano.

Entretanto, o ritmo acelerado do processo de conversão para o cinema sonoro no Rio e em São Paulo não foi repetido em outras localidades do país. Este artigo pretende demonstrar como a transformação do circuito nacional com a chegada dos talkies ocorreu de forma irregular e diferenciada nas várias regiões do Brasil, fornecendo um quadro mais amplo do mercado exibidor brasileiro. 
2. Abreviações utilizadas: Cine Magazine $(\mathrm{CM})$, Cinearte $(\mathrm{CI})$.

3. As salas de cinema eram classificadas conforme o luxo, conforto, lotação, localização e preço. Os principais filmes eram lançados primeiro nas melhores salas (os cinemas de primeira linha), sendo depois exibidos nas demais salas (fazendo o circuito).

\section{As estreias do cinema sonoro: primeira fase de conversão $(1929-1930)^{2}$}

A exemplo do pioneirismo das cidades de São Paulo e Rio de Janeiro, foi a região sudeste aquela cujo circuito lançador ${ }^{3}$ mais rapidamente se converteu para o cinema sonoro. A cidade de Niterói, então capital do estado do Rio de Janeiro, conheceu o cinema falado já em 3 de setembro de 1929, com o filme da Paramount A canção do lobo (dir. Victor Fleming, 1929). Como ocorrera na vizinha capital federal, em Niterói o Cine-Theatro Imperial, inaugurado no ano anterior, também expôs durante alguns dias, em seu hall de entrada, as caixas que vieram dos Estados Unidos com os equipamentos sonoros da Radio Corporation of America (RCA) (FREIRE, 2012b, p. 133-4).

Pouco tempo depois, o Photophone RCA também foi a opção para a inauguração da projeção sonora no Cinema Coliseu, lançado na cidade de Santos. O projetor RCA da sala santista era divulgado como "o $1^{\circ}$ aparelho instalado no estado de São Paulo e o $2^{\circ}$ no Brasil” (A Tribuna, 3 out. 1929, p. 10). Realmente, somente após o Imperial, de Niterói, e o Coliseu, de Santos, é que o Photophone foi utilizado em outros cinemas brasileiros.

Também em Santos, as caixas com aparelhagem importada ficaram expostas na sala de espera do Coliseu, principal cinema da empresa do Comendador Manoel Fins Freixo. A população foi, inclusive, convidada a assistir, no dia 18 de setembro, à abertura das 25 caixas de madeira, numa ostensiva exibição daquela que era considerada a mais moderna tecnologia cinematográfica que chegava à cidade. $\mathrm{O}$ primeiro filme sonoro exibido em Santos, Melodia da Broadway (dir. Harry Beaumont, 1929), estreou dez dias depois (A Tribuna, 17 set. 1929, p. 11; A Tribuna, 3 out. 1929, p. 10).

A exposição pública das caixas dos equipamentos sonoros importados - ocorrida, talvez pela primeira vez, no Palácio Theatro, no Rio de Janeiro (cf. FREIRE, 2012a, p. 255) - foi aparentemente uma estratégia repetida por vários exibidores brasileiros, em seus contextos locais. Aliás, ela foi citada por um jornalista carioca, dois anos mais tarde, ao lembrar que os "primeiros aparelhos americanos 
custavam uma pequena fortuna e o cinema que os adquiria deixava os caixotes em exposição na sala de espera, para mostrar o arrojo do proprietário" (Diário da Noite, 8 jun. 1931, p. 5).

Além da litorânea Santos, cidades economicamente mais desenvolvidas do interior de São Paulo também foram rápidas na conversão. Já no início de outubro de 1929 o jornal Correio Paulistano (5 out. 1929, p. 12) anunciava a chegada da aparelhagem norte-americana Pacent, importada pela Empresa Campos \& Cia, para a instalação do cinema sonoro no Cine São José, em Piracicaba. No dia 24 de outubro, o cinema piracicabano teria iniciado sua temporada de filmes sonoros com O pagão (dir. W. S. Van Dyke, 1929) (CARRADORE, 2002, p. 14).

Já em 19 de dezembro de 1929, o Theatro Carlos Gomes, de Vitória, estreou o cinema falado no Espírito Santo com um aparelho "dos mais aperfeiçoados e completos" da RCA. Como em outras cidades, o programa dessa estreia foi exatamente o mesmo de seis meses antes no Rio de Janeiro: o discurso do cônsul brasileiro Sebastião Sampaio, as canções de Yvette Rogel, e o já famoso "filme cantado, falado, bailado, musicado" Melodia da Broadway (Diário da Manhã, 19 dez. 1929, p. 8).

Depois da região sudeste, foi a região sul a que mais rapidamente incorporou a novidade, ainda em 1929. Em Curitiba, o luxuoso e recém-inaugurado Cine-Theatro Avenida, da J. Muzzillo \& Filhos, tinha alardeado a exibição de A divina dama (dir. Frank Lloyd, 1929) no dia 23 de outubro, com aparelhagem Movietone-Vitaphone RCA, mas "motivos técnicos" impediram o pioneirismo (República, 20 out. 1929, p. 9). A estreia do sonoro na cidade ocorreu, portanto, no Palácio Theatro, da Empresa Mattos Azevedo, com o antigo, mas ainda inédito O cantor de jazz (dir. Alan Crosland, 1927), “o primeiro filme falado visto no Paraná”, em 24 de outubro de 1929, exibido com som em discos. Reparado o problema, o Avenida só fez sua primeira exibição sonora no dia 25 de outubro (SCHWINDEN, 1991; ALVETTI, 1989, p. 28; República, 26 out. 1929, p. 7).

O Palácio Theatro de Curitiba pertencia à empresa do português Antonio Mattos Azevedo, e, em setembro de 1929, um 
4. Documento do Arquivo Pedro Lima, Cinemateca Brasileira. jornal catarinense dizia que já existia cinema falado no Rio, em São Paulo, em Santos e em Curitiba, tendo sido nesta cidade "instalado pela Empreza A. Mattos Azevedo". Em seguida, o jornal dizia que a mesma empresa instalaria brevemente o cinema falado em Florianópolis (Cine-Theatro, v. 1, n. 2, set. 1929, p. 1).

Datam também do final de 1929 as primeiras exibições do cinema sonoro em Porto Alegre. Enquanto Cláudio Todeschini (1986, p. 115) mencionou a exibição de Melodia da Broadway no Cinema Central, Susana Gastal (1999, p. 43) indicou que foi o Cine Apollo que teria introduzido a novidade, afirmando ainda que "entre 1929 e 1930, mais da metade dos cinemas de Porto Alegre adapta-se à novidade". De fato, a estreia do cinema sonoro na cidade ocorreu com a exibição de Melodia da Broadway no Cine Apollo, da Greco \&. C., no dia 8 de outubro de 1929, equipado com aparelhos Pacent e cobrando ingressos a caros quatro mil réis (A Federação, 7 out. 1929, p. 6, A Federação, 8 out. 1929, p. 4).

A primazia do Cine Apollo é confirmada ainda por carta escrita para o jornalista Pedro Lima por um amigo porto-alegrense, datada provavelmente de 15 de outubro de 1929, na qual era comentada a chegada da novidade à cidade. ${ }^{4}$

A correspondência dá uma boa amostra de críticas recorrentes na época da chegada do cinema sonoro, contrapostas, porém, à inegável atração que a novidade definitivamente gerava no público espectador:

Estreou aqui o tal de CINEMA FALADO. Boa droga, foi ao menos a minha opinião e a da maioria d'aqui. Até te escrevo esta, com este intuito. Não sei se porque o aparelho de reprodução do som do Cinema Apollo é muito primitivo, conforme ouvi dizer, ou não sei se o povo desta capital aprecia o cinema de fato, com $\mathrm{C}$ grande, como já te tenho dito muitas vezes. [...]

Mas, como estava te dizendo, o Cinema Apollo apresentou para a estreia do "talkie" o filme Broadway Melody, da Metro-Goldwin-Mayer, e primeiro, a título de "lever de ridau", na expressão dos anúncios, o trecho do Barbeiro de Sevilha cantado pelo Tita Ruffo. Mas 
o aparelho é uma victrola, digo, um gramofone e dos mais ordinários, piores do que os existentes nos [...] "sertões de Pindamondagava", ou coisa que o valha e, de vez em quando, o tal de aparelho desandava e tome o homem falando pela boca da mulher, e vice-versa, o povo desandava a bater com os pés como se fora uma estrebaria e... acabava-se a parte. $\mathrm{O}$ fato não agradou, $\mathrm{e}$ agora a Paramount promete para breve no Carlos Gomes um outro aparelho, desta vez, porém, um aparelho muito melhor, de oitenta contos, segundo dizem. [...]

Dizem que o Guarany vai também botar o tal cinema, espero que seja ao menos com uma vitrola em vez de gramofone.

Ainda a respeito de Porto Alegre, também é importante mencionar a notícia do jornal O Estado do Rio Grande, de 12 de março de 1930 (apud GASTAL, 1999, p. 44), indicando ter sido a Empresa Sirângelo Irmãos que introduziu na cidade o verdadeiro sistema sonoro, “com aparelhos adquiridos na Radio Corporation Association", que no Brasil, além de São Paulo e Rio de Janeiro, só existiriam até então em Porto Alegre. Os irmãos Paschoal, Francisco e Salvador Sirângelo eram os proprietários do Cine Central, que deve ter adquirido um Photophone conjugado da RCA de melhor qualidade do que o criticado som em discos Pacent instalado no Apollo.

Assim como aconteceu em Niterói, Santos, Vitória, Curitiba e Porto Alegre, o Photophone RCA também foi adotado em Salvador. Walter da Silveira (1978, p. 73) citou publicidade relatando que a novidade foi inaugurada na capital baiana pelo Cine Guarani, em 19 de abril de 1930, com Inocentes de Paris (dir. Richard Wallace, 1929), usando "os mais modernos e custosos aparelhos da Radio Corporation". A inauguração do cinema falado na Bahia teria sido incentivada pelo gerente da Paramount nesse estado, Manoel Araújo. Após visitar São Paulo durante o congresso sul-americano da empresa no ano anterior, o distribuidor teve a oportunidade de conhecer a novidade na capital paulista e convenceu o Sr. Cel. Ponde "sobre a instalação do novo sistema no seu bem frequentado cinema Guarany" (Mensageiro Paramount, v. 12, n. 3, set. 1930, p. 28). 
Após este que foi um "verdadeiro acontecimento social na capital baiana” (Mensageiro Paramount, v. 12, n. 3, set. 1930, p. 28), dois outros cinemas de Salvador também compraram aparelhagem RCA, o Cine Lyceu e o Cine Glória. Aliás, Cinearte (v. 5, n. 221, 21 mai. 1930, p. 29) informou que o Cine Gloria, "casa de recente construção e de propriedade do Dr. Simões Filho", teria sido responsável pela inauguração do cinema sonoro na Bahia com o filme Garotas modernas (dir. Harry Beaumont, 1928) - originalmente lançado no Rio em fevereiro de 1929 com cópia silenciosa, mas relançado sete meses depois em versão com música sincronizada. Conforme Silveira (1978, p. 73), o Cine Liceu estreou a sua aparelhagem sonora no dia 21 de junho de 1930, com o filme Broadway (dir. Paul Fejos, 1930).

Antes disso, por volta de janeiro de 1930, o filme falado estreou em Belo Horizonte, com a exibição do célebre Melodia da Broadway (CI, v. 5, n. 212, 19 mar. 1930, s.p.). Poucos meses depois da capital mineira foi a vez de Juiz de Fora. Conforme relato da correspondente de Cinearte de pseudônimo Mary Polo, a cidade vinha recebendo com curiosidade o tal cinema sincronizado, mesmo que por meio de sessões de produções nacionais acompanhadas por discos de vitrola, ou de filmes americanos musicados, mas sem diálogos. O sucesso foi verdadeiramente alcançado com a estreia em Juiz de Fora do filme falado e cantado Hollywood revue (dir. Charles Reisner, 1929), apesar das alardeadas deficiências do sistema de som em discos (CI, v. 5, n. 219, 7 mai. 1930, s.p.).

Como foi mencionado no caso de Salvador, foi realmente em 1930 que o cinema sonoro estreou nas melhores salas das capitais nordestinas. Luciana Corrêa de Araújo (2011, p. 33 ) citou reportagem comentando a chegada de navio de quarenta volumes de aparelhagem de som para o Theatro do Parque, cinema de Recife pertencente a Luiz Severiano Ribeiro que, em março de 1930, exibiu os filmes A divina dama e Melodia da Broadway. Em maio, Cinearte reportava que o primeiro filme sonoro lançado em Recife "foi Broadway Melody, que inaugurou a temporada dos 'talkies', mantendo-se oito dias no cartaz do Cinema Parque, um dos mais modernos do Norte" (CI, v.5, n. 221, 21 mai. 1930, p. 
29.) Luciana Araújo (2007, p. 75) esclarece ainda que, reformado no ano anterior, o Theatro Parque havia se tornado a principal e mais luxuosa sala de Recife.

O fato é que a conversão para o cinema sonoro atingiu em seus primeiros doze meses os melhores cinemas daquelas reconhecidas como as principais praças exibidoras do país, que consistiam nas capitais e cidades mais desenvolvidas do sudeste, sul e nordeste. Essa pode ser definida como a primeira fase do processo de adaptação à projeção sonora em âmbito nacional.

Essa questão obviamente também está relacionada ao poderio das empresas regionais. Já dominando o mercado exibidor nordestino, além de Pernambuco, o exibidor Severiano Ribeiro, por exemplo, também foi responsável pela estreia do cinema sonoro no Ceará, com a exibição, a partir do dia 19 de junho de 1930, de Melodia da Broadway no Cine Moderno de Fortaleza. As latas do filme e o operador vieram de navio do Rio de Janeiro, assim como tinham vindo semanas antes os técnicos e os equipamentos de som em discos de fabricação nacional (LEITE, 1995, p. 359-62).

Já em Aracaju, o cinema sonoro teria estreado alguns meses depois, com Hollywood revue, exibido na capital sergipana a partir de 28 de novembro de 1930 (DANTAS, 1971).

Afora as capitais nordestinas, o cinema falado também se espalhou ao longo de 1930 pelas mais prósperas cidades do interior paulista como Ribeirão Preto, Campinas e Rio Preto. Conforme a revista Mensageiro Paramount (v. 12, n. 4, out. 1930, p. 11), São Paulo era o Estado que, naquele ano, já dispunha do maior número de cinemas adaptados "ao novo sistema". Não apenas o estado mais rico da federação, São Paulo era também aquele que possuía o maior número de salas de cinema do Brasil.

\section{Difícil expansão: segunda fase de conversão (1931-1933)}

Apesar do investimento dos principais cinemas das maiores cidades brasileiras, a primeira fase de conversão para o cinema sonoro foi restrita a uma parte pequena do circuito exibidor nacional. Um editorial de Cinearte (v. 5, n. 211, 12 mar. 1930, p. 3) se dedicou a explicar uma das razões para isso: 
O maior embaraço para a divulgação do filme sonoro entre nós como em quase toda parte consiste no exagerado preço das instalações exigido pelos fabricantes, que absolutamente não se coaduna com os recursos financeiros da maioria dos proprietários de Cinemas, menos ainda com as possibilidades econômicas dos pequenos núcleos de população do interior.

Devido aos altos custos, o editorialista apostava que o interior do Brasil continuaria por muitos anos ainda como mercado para o filme silencioso. E isso não se daria apenas pelo alto custo das instalações (projetores, retificadores, alto-falantes etc.), mas também pelo elevado preço de aluguel das cópias dos talkies cobrado pelas distribuidoras, o que se transformava em "problema de suma gravidade" para os exibidores do interior (CI, v. 5, n. 222, 28 mai. 1930, p. 3).

Eram fatores como esses - aliados às dificuldades iniciais experimentadas para se adaptar satisfatoriamente os filmes falados em inglês ao gosto e à compreensão das plateias brasileiras - que provocavam entusiasmo nos produtores brasileiros que ainda investiam nos filmes silenciosos ou apenas musicados com o objetivo de explorar os circuitos secundários de exibição. Esse otimismo se fundamentaria no fato de que essa situação se manteria semelhante um ano depois. Afinal, em junho de 1931, cerca de dois anos após a estreia do filme sonoro em São Paulo e no Rio, o panorama do mercado exibidor brasileiro era assim resumido no editorial de Cinearte (v. 6, n. 276, 10 jun. 1931, p. 3):

As grandes casas de exibição fizeram enormes despesas com o aparelhamento, as menores, à míngua de recursos, buscaram derivativos nos aparelhos sincronizados [por discos]; os mais modestos ainda sujeitaram-se a programar filmes velhos ou então as versões silenciosas dos filmes sonoros ainda piores do que aqueles.

Duas semanas mais tarde, o editorial da revista especulava: "País pobre, cremos que não existe em todo o país ainda cinquenta cinemas dotados de aparelhos para a reprodução perfeita do filme 
5. O sistema Vitaphone usava discos especiais - de maior dimensão e duração -, diferentes dos discos empregados pela indústria fonográfica. sonoro" (CI, v. 6, n. 278, 24 jun. 1931, p. 3 [grifo do texto]). O adjetivo "perfeita" indicaria que muitos cinemas vinham exibindo filmes sonoros precária ou improvisadamente nos últimos dois anos, isto é, por meio de discos comuns executados em vitrolas ou em contrafações canhestras do Vitaphone. ${ }^{5}$

Mas mesmo que de forma precária ou improvisada, a exibição de filmes sonoros demorava a chegar a diversas localidades do Brasil, como Caratinga, interior de Minas Gerais. O Cine Caratinga, o único da cidade, inaugurou seu projetor Vitaphone em 14 de outubro de 1932, com o já antigo Broadway, "superando as ingentes dificuldades que representam as caríssimas adaptações que foram necessárias para dotar Caratinga de uma casa de diversões à altura de suas necessidades e de seu meio social elevado e culto" $(O$ município, v. 6, n. 134, 6 out. 1932, p. 1, 6).

Realmente, os caratinguenses deviam se orgulhar, pois, na mesma época, um leitor de Manaus reclamava na revista Cinearte (v. 7, n. 354, 7 dez. 1932, p. 35) que sua "linda cidade [...] desconhece o cinema falado e todos os filmes são mudos e na mor parte antigos!”. A pesquisa de Selda Vale Costa (1988, p. 168) sobre o cinema em Manaus cita artigo da revista Victoria-Regia, de fevereiro de 1933, elogiando "o cinema falado", nos fornecendo subsídios para concluir que a novidade finalmente havia chegado à capital amazonense naquele início de 1933.

Apesar dos avanços, o real limite da conversão geral do circuito exibidor nacional era demonstrado por reportagem da Cine Magazine publicada no final de 1933, na qual o correspondente da revista em Recife traçou um quadro da situação no norte do país. Se em Pernambuco, o principal estado da região, havia apenas 26 cinemas sonoros, a situação relatada pela revista nos demais estados da região norte e nordeste era muito mais tímida, cada um deles contando com apenas três cinemas sonoros (Alagoas e Ceará), dois (Rio Grande do Norte, Amazonas) ou mesmo somente um (Paraíba, Maranhão, Piauí).

Em situação significativamente melhor que os demais estados do norte estaria o Pará. Como a capital Belém tinha um tradicional e próspero circuito de salas, em 1933 o estado já contava com oito 
6. A maior parte das salas brasileiras então já adaptadas exibia os filmes sonoros em apenas um projetor, o que exigia de três a cinco intervalos, em geral, durante a projeção de um longa-metragem.
7. Documentos do Arquivo Família Ferrez, Arquivo Nacional. a nove salas equipadas para o sonoro, sendo ressaltado que apenas uma possuía sistema duplo - isto é, era dotada de dois projetores, o que permitia a troca de rolo (e, se fosse o caso, de disco) sem interrupção do filme (CM, n. 7, nov. 1933, p. 14, 17, 19). ${ }^{6}$

Deste modo, embora a conversão para o cinema sonoro avançasse lentamente em todo o Brasil - assumindo um ritmo mais acelerado apenas nas principais capitais -, fica evidente que em muitos cinemas do país ela tinha sido feito de forma restrita. Afinal, num diagnóstico do circuito exibidor de Porto Alegre publicado em Cinearte (v.7, n.333, 13 jul. 1932, p. 8), afirmava-se que das 19 salas da cidade, três delas ainda "usam adaptações de Vitaphone", o que consistia provavelmente em toca-discos comuns. Já no relato de Cine Magazine sobre o circuito exibidor de Pernambuco em 1933, se apontava que a maioria dos cinemas do estado possuía "aparelhos Vitaphone ou nacionais, excetuando-se algumas instalações em Recife que são uma Western e outra RCA no Parque Moderno."

Para além dos tapeafones e cavatones - simples vitrolas improvisadas -, a demanda pelo cinema sonoro por parte de exibidores menos capitalizados estimulou a fabricação nacional de projetores e instalações sonoras mais baratos e simples. Esse quadro que incentivava a produção de equipamentos brasileiros era confirmado em reportagem que destacava o fato de a concorrência estar fazendo os preços diminuírem. Vinha sendo, sobretudo, por meio da venda de aparelhos sincronizados nacionais que se chegava àquela situação que ia "permitindo as instalações estenderem-se pelo interior do país" (CI, v. 6, n. 278, 24 jun. 1931, p. 3).

A complexidade desse processo pode ser verificada com mais detalhes nas cartas enviadas por Eduardo Ferrez, então residindo em Porto Alegre, a seu pai, Julio Ferrez, da companhia exibidora e distribuidora Marc Ferrez \& Filhos, no Rio de Janeiro, nos últimos meses de $1931{ }^{7}$

Por meio da correspondência, podemos notar que a maioria das salas gaúchas convertidas estava em Porto Alegre, onde, segundo Eduardo, "todos os cinemas estão equipados com o sonoro e não vi ainda um filme mudo em cartaz" (carta de 3 dez. 1931). Apesar disso, os grandes cinemas porto-alegrenses não estariam dando 
bons resultados financeiros, sobretudo diante do caríssimo preço de aluguel das cópias dos talkies de Hollywood. Mas ele notava ainda que a alternativa de distribuir filmes mudos não era boa, pois nos melhores cinemas ninguém mais queria saber de cinema silencioso. Já nos cinemas de bairro, além de depender da boa vontade dos exibidores, o distribuidor teria que arcar com os gastos de propaganda e da compra de discos para o acompanhamento sonoro da fita muda - sem falar do trabalho de "sincronizá-la mais ou menos, pois neste ponto de vista eles [os exibidores] não entendem muito de música" (carta de 11 dez. 1931). Ou seja, nessa operação se acabaria perdendo dinheiro, pois o "máximo que [os exibidores] podem pagar seria o que eu teria de tirar do meu bolso para sincronizar o filme" (carta de 3 dez. 1931).

Se esses complicadores para a distribuição de cópias mudas não fossem o bastante, Eduardo Ferrez se surpreendia com o fato dos donos de salas de cinema do interior do estado fazerem questão absoluta de seus filmes serem "completamente falados e ainda em inglês, apesar de não compreenderem nada” (carta de 5 dez. 1931).

Mesmo com as dificuldades, o processo de interiorização do cinema sonoro, ainda relativamente reduzido em 1931, ganhou um grande impulso em 1932 e 1933, com a aceleração da conversão, por exemplo, dos circuitos secundários das grandes capitais, assim como dos melhores cinemas das cidades de médio porte. No Rio Grande do Sul, podemos estimar que a proporção de cinemas sonoros passou, entre 1931 e 1933, de 15\% a 42\%.

Esse avanço, no entanto, conheceu pouco depois uma acentuada diminuição, aparentemente devido à saturação do mercado das capitais brasileiras. Em seu estudo sobre o cinema no Paraná, Celina Alvetti (1989, p. 51) afirmou que "depois de um surto de inaugurações de aparelhamento sonoro, entre 1930 e 1933, elas foram rareando, entrando no ritmo normal de exibição e melhorias. Algumas cidades [...], no entanto, levaram anos para ter o seu sonoro".

Portanto, a partir desse momento, os clientes que faltavam ser conquistados eram, na maior parte, os pequenos exibidores das cidades do interior do país, principalmente nas regiões mais 
distantes dos grandes centros urbanos. Este era o caso, por exemplo, do Cine Parisien, o único de Cuiabá, inaugurado em 1912 e desde então funcionando num precário barracão de zinco. Fechado em 1930, o Cine Parisien só foi reinaugurado em 30 de março de 1933 como Cine Teatro República. Dotado de aparelhagem de som em discos, os equipamentos foram estreados com Marrocos (dir. Josef von Sternberg, 1930), filme falado da Paramount exibido dois anos antes no sudeste, mas que era o primeiro talkie visto e ouvido em Mato Grosso (ALENCASTRO, 2012, p. 91).

Esse atraso do mercado exibidor brasileiro motivou, entre fins de 1933 e meados de 1934, uma verdadeira campanha pela conversão para o cinema sonoro nas páginas de Cine Magazine, periódico cujos anunciantes incluíam distribuidores e fabricantes de equipamentos diretamente interessados nesse assunto. No editorial da edição de dezembro de 1933, intitulado "Uma questão palpitante", L. S. Marinho indagava o motivo de ainda existirem tantos cinemas silenciosos no Brasil mesmo com a popularidade dos aparelhos nacionais e diante do fato de que "os filmes mudos estão absolutamente banidos de circulação" (CM, n. 8, dez. 1933, p. 3). Três meses depois, em editorial no qual lamentava a falta de boas salas de exibição para os "modernos filmes de grande sucesso", Marinho novamente comentava a existência de aparelhagem sonora de boa qualidade e de todos os preços. Assim sendo, "não se compreende que exibidores persistam em manter seus cinemas sem aparelhos para filmes falados!" (CM, n. 11, mar. 1934, p. 3).

De fato, apesar da crescente oferta de equipamentos nacionais mais baratos para atender os pequenos exibidores e do avanço na adaptação do mercado exibidor ao filme sonoro nos anos anteriores, a conversão do circuito nacional ainda estava distante de ser completa. Em 1935, a situação era assim descrita por José. J. de Barros na Sessão Técnica de Cine Magazine: (n. 22, fev. 1935, p. 18): "Há ainda no território nacional, um grande número de cinemas mudos, um número ainda maior de salas completamente paradas há anos, e um número considerável de cinemas equipados somente com aparelhos para reprodução de som em discos". 
Segundo o autor do texto, eram quatro as razões para esse estado de coisas: 1) o aumento no preço do aluguel das cópias de filmes sonoros; 2) o custo elevado dos aparelhos de som; 3) as más experiências de colegas com aparelhos de baixa categoria; 4) as crises econômicas regionais.

Mas, se José. J. de Barros afirmava que a tendência era a baixa progressiva dos preços dos programas (isto é, do aluguel das cópias) com o aumento da oferta de filmes sonoros por diferentes distribuidores, ele argumentava ainda que o custo dos equipamentos também não representaria um empecilho real:

Já existem no mercado marcas de aparelhos, oferecidos por firmas de grande idoneidade, que cuidaram com especial carinho de organizar equipamentos apropriados para pequenas salas por preços absolutamente razoáveis, por menos do que o custo de um automóvel Ford de segunda mão, e em condições de tanta suavidade que mais seria de causar suspeita.

Aos exibidores que argumentavam que o investimento não era vantajoso, Barros respondia com a ameaça da concorrência local: "Esteja certo de que existe no lugar uma pessoa que terá intimamente o desejo de montar um cinema muito melhor que o atual, mas não o faz porque não dá para dois [...] e não quer aborrecimento".

Barros citava ainda a vantagem de se poder exibir nos cinemas sonoros "cenas grandiosas de espetáculos que, ao vivo, são vistos apenas nas grandes cidades e para os ricos". Por fim, em relação à experiência frustrada de alguns exibidores com certos projetores sonoros, o autor do artigo responsabilizava por isso os colegas afoitos que adquiriram aparelhos de amadores.

\section{Padronização tecnológica (1934-1935)}

Além dos negócios das empresas fabricantes de equipamentos - o autor do artigo citado, José J. de Barros, por exemplo, era diretor de uma delas, a Cinephon -, a campanha pela conversão à projeção 
sonora dos cinemas brasileiros em revistas como Cine Magazine atendia também aos interesses comerciais de outros anunciantes.

Afinal, as agências distribuidoras desejavam padronizar a circulação de cópias no mercado nacional, uma vez que o cinema sonoro havia trazido um aumento de seus gastos com a necessidade de lançamento de diferentes versões do mesmo título. Se inicialmente foi necessário distribuir simultaneamente versões sonoras e mudas para atender tanto aos cinemas já convertidos quanto àqueles ainda não aparelhados, posteriormente foi preciso lançar os mesmos talkies em dois sistemas sonoros diferentes (Vitaphone e Movietone).

Entretanto, com a ampla adoção do mais simples, prático e econômico som ótico como padrão da indústria, o lançamento de cópias com som em discos - para atender exclusivamente os cinemas que tinham instalado apenas o Vitaphone - se tornou cada vez mais um gasto extra a ser imediatamente dispensado.

Deste modo, em março de 1934, uma reportagem sobre as futuras estreias da Warner (o estúdio de Hollywood que lançara o próprio Vitaphone) no país terminava com um alerta:

E, agora, não hesite mais [...] moderniza o seu cinema,
dotando-o com a aparelhagem necessária ao vitorioso
sistema MOVIETONE, pois definitivamente suspensa
pela Warner Brothers-First National e as demais grandes
produtoras, a importação de cópias para VITAPHONE,
assim, não mais teremos discos fonográficos, de difícil e
arriscada embalagem e que podem falhar! Somente o
MOVIETONE é garantido! (CM, n. l1, mar. 1934, p. 8).

A importância dessa padronização - que não só apresentava vantagens práticas, como traria benefícios econômicos significativos para as companhias distribuidoras - possivelmente explica um tom quase de terrorismo adotado num editorial da mesma revista, quatro meses depois: 
sendo eliminados devido às dificuldades de transporte, $\mathrm{e}$ pela facilidade de prejuízos que acarretam.

Agora mesmo, acabamos de receber da Fox Film uma comunicação de que todos os seus filmes serão unicamente pelo sistema Movietone: os discos não serão mais importados, por isso, fazemos uma especial recomendação a todos os exibidores cujos aparelhos não estão ainda adaptados para o uso dos filmes Movietone, providenciarem no sentido de modificar suas instalações (CM, n. 15, jul. 1934, p. 3).

A padronização da distribuição de cópias sonoras no mercado brasileiro para o som ótico demandava a instalação do sistema Movietone na maior parte do circuito exibidor. Tratava-se de um esforço considerável, uma vez que, em 1933, 54\% dos cinemas brasileiros adaptados para o cinema sonoro ainda estavam equipados apenas com o sistema de som em discos, isto é, o Vitaphone e seus congêneres (CI, v. 8, n. 370, 1 jul. 1933, p. 37).

Embora até 1929 todos os projetores sonoros comercializados mundialmente possuíssem o sistema de som em discos, a mudança para o som ótico havia sido rápida. No final de 1930, a maioria dos cinemas norte-americanos já projetava filmes em Movietone, Photophone ou qualquer outro tipo de som ótico genérico. Em março de 1932, a revista Film Daily apontou que, dentre as salas convertidas nos EUA, 43\% tinham apenas som ótico, $33 \%$ possuíam os dois sistemas e $24 \%$ apenas o som em discos (CRAFTON, 1997, p. 146, 148, 571). Já em 1933, apenas 2,6\% dos cinemas norte-americanos ainda usariam exclusivamente o som em discos, segundo o Motion Picture Almanac. Na França, por sua vez, esse sistema estava praticamente extinto desde o final de 1930 (GUBERN, 1993, p. 11).

Assim, em 1934, provavelmente com cerca de metade de seu circuito ainda dependente de filmes com som em discos, o mercado exibidor brasileiro era forçado a se adaptar ao som ótico.

Pressionados, portanto, pela falta de filmes silenciosos e logo também pela escassez até mesmo de cópias com som em discos, os pequenos exibidores brasileiros viram-se obrigados a converterem- 
se para a projeção sonora em som ótico, fecharem as portas ou passarem a funcionar como teatros ou casas de espetáculos. Ou seja, o aumento da porcentagem de cinemas convertidos também esteve inevitavelmente ligado à diminuição do próprio circuito brasileiro, devido ao fechamento, provisório ou definitivo, de inúmeros pequenos cinemas. O mercado exibidor brasileiro sem dúvidas encolheu na segunda metade da década de 1930.

Enfim, essa fase final foi marcada pela substituição dos Vitaphones, vitrolas e tapeafones inicialmente instalados por novos equipamentos do "verdadeiro cinema falado" (som ótico) nas pequenas salas que estavam fechadas ou vinham sobrevivendo precariamente. A região centro-oeste parece ter sido a última fronteira a ser conquistada pelo filme falado, o que teria ocorrido nesse momento. Baseando-se em pesquisas de Marinete Pinheiro (2010, p. 78-9) e outros documentos, pode-se indicar que em 1937, com a reforma do Cineteatro Santa Helena e a importação de equipamentos da Europa, Campo Grande viu a primeira exibição de um filme sonoro em som ótico. Também em 1937 foi inaugurado o Cine Progresso, o primeiro cinema a exibir filmes falados no estado de Goiás (LEÃO, BENFICA, 2009, p.1)

Finalmente ocorria a conversão da última parte do circuito exibidor brasileiro. Em junho de 1935, Cinearte (v. 10, n. 417, 15 jun. 1935 , p. 24) noticiou a instalação de aparelho falado no único cinema da cidade de Cafelândia, interior de São Paulo. Outro exemplo é o cinema de Cambuí, em Minas Gerais, sonorizado apenas em 1937 (BARRO, 2008, p. 55). Foi nesse mesmo ano que o cinema sonoro também foi inaugurado no Teatro Municipal de Morretes, cidade no litoral do Paraná (ALVETTI, 1989, p. 51). Os cinemas de pequenos municípios como Três Rios, no interior do estado do Rio de Janeiro, e Conceição do Rio Verde, no sul de Minas Gerais, foram reaparelhados somente em 1938 (CM, n. 64, ago. 1938, p. 14, 16). Por fim, já no final da década, o Jornal do Exibidor (v. 2, n. 35, 15 jan. 1939, p. 2) anunciava a inauguração tardia do cinema sonoro no município de Antonio Caetano, no Espírito Santo. 


\section{Conclusão}

À guisa de conclusão, podemos tentar resumir brevemente o processo descrito anteriormente. Inicialmente, a conversão das salas de cinema brasileiras atingiu, entre 1929 e 1930, apenas os melhores cinemas das grandes cidades do país, que foram dotados de projetores conjugados Western Electric. Rio de Janeiro e São Paulo testemunharam a rápida conversão de parte significativa de seus circuitos de primeira linha. Outras capitais da região sul, sudeste e nordeste apressaram-se para acompanhar a novidade com a conversão de seus cinemas mais modernos e lucrativos.

A maior parte dos exibidores regionais adquiriu, nessa fase, projetores Photophone RCA, que teriam a mesma qualidade do Western Electric, mas com preços e condições mais vantajosas. Uma evidência da forte campanha da empresa norte-americana no país é uma nota do jornal gaúcho A Federação (26 set. 1929, p. 4) que noticiava a presença do Sr. Edward C. Adler, da RCA, em Porto Alegre, negociando todos os tipos de projetores sonoros. Tendo vendido vários aparelhos na capital gaúcha, o representante da empresa partiria em breve para o interior do estado atrás de novos compradores.

Outra estratégia da empresa norte-americana era incentivar o uso do Photophone em salas mais luxuosas que promovessem a marca. Em 1929, o gerente do Cassino Atlântico, em Copacabana, assegurou que a RCA "ofereceu sem custo equipamento de projeção sonoro ao Atlântico" (GONZAGA, 1996, p. 194).

Num segundo momento, enquanto salas lançadoras de outras cidades importantes do interior dos estados da região sul e sudeste também se adaptavam à novidade, o cinema sonoro finalmente chegava às capitais do norte e nordeste. Em seguida, quando a conversão atingia a última parte do circuito do Rio e São Paulo (nesse caso, os cinemas de bairro), ela chegava aos principais cinemas de cidades como Manaus ou João Pessoa. Desta forma, em meados dos anos 1930, enquanto espectadores dos centros mais desenvolvidos economicamente do país já não tinham mais locais onde assistir a filmes silenciosos, o público de pequenos municípios do interior do Brasil entrava em contato pela primeira 
vez com os afamados talkies. Como foi dito, essa situação impulsionou a fabricação de equipamentos nacionais de marcas como Fonocinex, Cinephon, Cinevox, Cinetom, Centauro, Triunfo, Sólidus, entre outras.

A conversão virtualmente total do circuito brasileiro ocorreu apenas nos últimos anos da década de 1930, quando chegou a cerca de $90 \%$ o número de salas adaptadas para o cinema falado - consolidada com a padronização do som ótico e da legendagem. Nos rincões do país, porém, certamente ainda persistiram exibições silenciosas (com ou sem música ao vivo) ou com acompanhamento musical mecânico não sincronizado. Portanto, o filme falado só chegou às modestas salas das pequenas cidades brasileiras no momento em que os palácios de cinema do Rio e São Paulo já incorporavam outras novidades, como os modernos sistemas de ar-condicionado, tema de uma nova campanha da revista Cine Magazine (FREIRE, 2011, p. 312).

Deste modo, a situação esboçada neste artigo parece justificar um comentário irônico em A Scena Muda (n. 1019, 1 out. 1940, p. 4-5) quando era anunciado que o ator Genésio Arruda retornaria ao cinema na nova produção da Cinédia O dia é nosso (dir. Milton Rodrigues, 1941). Segundo o jornalista, o filme anterior do cômico caipira, O campeão de foot-ball (1931), feito dez anos antes e sonorizado em discos 78rpm para execução em vitrolas comuns, era uma "película que ainda se exibe por esses ‘Brazis' a fora". A ironia reside no fato de que a brutal desigualdade de um "país pobre" - como já havia ressaltado Cinearte - e formado por diferentes "Brasis", não podia deixar de ser refletida na coexistência entre o moderno e o arcaico no circuito exibidor cinematográfico brasileiro. Essa desigualdade tornou-se especialmente aguda durante o processo de conversão para a projeção sonora. 


\section{Referências}

ALENCASTRO, A. "O cinema em Mato Grosso: Patrimônio cultural”. Revista do Instituto Histórico e Geográfico de Mato Grosso, Cuiabá, n. 70, 2012.

ALVETTI, C. R. P. O cinema brasileiro na crônica paranaense dos anos trinta. Dissertação (Mestrado) - Universidade de São Paulo, São Paulo, 1989.

ARAÚJO, L. C. “O cinema em Pernambuco nos anos 1930”. In: I Jornada Brasileira do Cinema Silencioso. Cinemateca Brasileira, São Paulo, 2007.

"Recife na rota do mundo: o Porto do Recife nos filmes silenciosos pernambucanos”. In: CANEPA, L. et al (Orgs.). Estudos de cinema e audiovisual Socine. v. 2. São Paulo: Socine, 2011 .

BARRO, M. José Carlos Burle: drama na chanchada. São Paulo: Imprensa Oficial, 2008.

CARRADORE, H. P. Síntese das memórias: 1900-2002. Piracicaba: Instituto Histórico e Geográfico de Piracicaba, 2002. Disponível em: <http://www.ihgp.org.br/acervo/publicacoes/pdf/09.pdf.>. Acesso em: 16 abr. 2013.

COSTA, S. V. Eldorado das ilusões: cinema e sociedade: Manaus (1897-1935). São Paulo: PUC, 1988.

CRAFTON, D. The talkies: American cinema's transition to sound, 1926-1931. Berkeley: University of California Press, 1997.

DANTAS, V. “Assim nasceu o cinema em Aracaju”. Jornal da Cidade, 13 set. 1971. Disponível em: <http://www.mnemocine.art. br>. Acesso em: 5 jun. 2013.

FREIRE, R. L. “A febre dos sincronizados: os primeiros meses da exibição de filmes sonoros no Rio e em São Paulo em 1929”. In: SOUZA, G. et al (Orgs.). XIII Estudos de cinema e audiovisual Socine. v. 2. São Paulo: Socine, 2012a. 
Cinematographo em Nictheroy: história das salas de cinema de Niterói. Niterói: Niterói Livros, 2012b.

“O 'conforto moderno': a refrigeração nas salas de cinema do Rio de Janeiro na primeira metade do século XX". Revista do Arquivo Geral da Cidade do Rio de Janeiro, Rio de Janeiro, v. 5, 2011.

GASTAL, S. Salas de cinema: cenários porto-alegrenses. Porto Alegre: U E, 1999.

GONZAGA, A. Palácios e poeiras: 100 anos de cinemas no Rio de Janeiro. Rio de Janeiro: Record, 1996.

GUBERN, R. "La traumática transición del cine español del mudo al sonoro". In: ACTAS DEL IV CONGRESO DE LA A.E.H.C., 1992, Espanha. Madrid: Editorial Complutense, 1993. Disponível em: <http://www.cervantesvirtual.com>. Acesso em: 5 abr. 2013.

LEÃO, B.; BENFICA, E. "Goiás no século do cinema”. Mnemocine, 2009. Disponível em: <http://www.mnemocine.art.br>. Acesso em: 3 mai. 2013.

LEITE, A. B. Fortaleza e a era do cinema: pesquisa histórica (1891/1931). Fortaleza: Secretaria de Cultura, 1995.

PINHEIRO, M. "História dos cinemas de Campo Grande/MS". Cadernos de Pesquisa, Rio de Janeiro, 2010.

SCHWINDEN, A. Palácio Avenida. Curitiba: Casa de Ideias, 1991.

SILVEIRA, W. A história do cinema vista da província. Salvador: Fundação Cultural do Estado da Bahia, 1978.

TODESCHINI, C. "Os velhos cinemas de Porto Alegre". Filme Cultura, Rio de Janeiro, n. 47, ago. 1986. 


\section{Periódicos citados ${ }^{8}$}

8. Consultados no acervo da

Cinemateca do MAM-RJ, na Biblioteca Nacional, na Hemeroteca

Digital Brasileira (http://hemerotecadigital.bn.br/), no acervo André Malverdes e no acervo pessoal do autor.
A Federação, Porto Alegre, 26 set. 1929, p. 4; 7 out. 1929, p. 6; 8 out. 1929, p. 4.

A Scena Muda, Rio de Janeiro, n. 1019, 1 out. 1940, p. 4-5.

A Tribuna, Santos, 17 set. 1929, p. 11; 3 out. 1929, p. 10; 3 out. 1929 , p. 10.

Cinearte, Rio de Janeiro, v. 5, n. 211, 12 mar. 1930, p. 3; v. 5, n. 212, 19 mar. 1930, s.p.; v. 5, n. 219, 7 mai. 1930, s.p.; v. 5, n. 221, 21 mai. 1930, p. 29; v. 5, n. 221, 21 mai. 1930, p. 29; v. 5, n. 222, 28 mai. 1930, p. 3; v. 6, n. 276, 10 jun. 1931, p. 3; v. 6, n. 278, 24 jun. 1931, p. 3; v. 6, n. 278, 24 jun. 1931, p. 3; n. 354, 7 dez. 1932, p. 35; v. 7 , n. 333,13 jul. 1932 , p. 8 ; v. 8 , n. 370,1 jul. 1933 , p. 37 ; v. 10, n. 417,15 jun. 1935 , p. 24.

Cine Magazine, Rio de Janeiro, n. 7, nov. 1933, p. 14, 17, 19; n. 8, dez. 1933 , p. 3; n. 11, mar. 1934, p. 3; n. 11, mar. 1934, p. 8; n. 15, jul. 1934, p. 3; n. 22, fev. 1935, p. 18; n. 64, ago. 1938, p. 14, 16.

Cine-Theatro, Florianópolis, v. 1, n. 2, set. 1929, p. 1.

Correio Paulistano, São Paulo, 5 out. 1929, p. 12.

Diário da Manhã, Vitória, 19 dez. 1929, p. 8.

Diário da Noite, Rio de Janeiro, 8 jun. 1931, p. 5.

Jornal do Exibidor, Rio de Janeiro, v. 2, n. 35, 15 jan. 1939, p. 2.

Mensageiro Paramount, New York, v. 12, n. 3, set. 1930, p. 28; v. 12, n. 4, out. 1930, p. 11.

O Município, Caratinga, v. 6, n. 134, 6 out. 1932, p. 1, 6.

República, Curitiba, 20 out. 1929, p. 9; 26 out. 1929, p. 7. 